\title{
Menciptakan Lapangan Kerja Bagi Fresh Graduate Melalui Program Workshop Dan Seminar Move On Entrepreneur
}

\author{
Alfatih S.Manggabarani ${ }^{\text {a, },{ }^{*},}$, NunukTriwahyuningtyas ${ }^{\mathrm{b}, 2}$

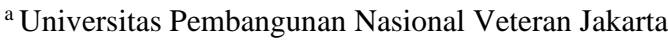 \\ b Universitas Pembangunan Nasional Veteran Jakarta \\ 1 alfatihsikki@gmail.com* \\ * corresponding author
}

Keywords

Entrepreneur

Fresh Graduate

Job Opportunity
Through this service, we hope to empower the optimal candidates, so that new graduates can take part in Smart Jurus Seminars and Workshops Gaining Business Wealth. "MOVING SEMINARS AND WORKSHOPS IN ENTREPRENEURS. To Get Profit Through Business. Why If You Want To Be Successful and Rich You Must Be An Entrepreneur? "This is one way to share entrepreneurial knowledge with alumni, especially the younger generation, so that someday they can become strong and successful entrepreneurs in the future. The workshop participants were 100 new graduates in 2017/2018 before the graduation ceremony.

\section{PENDAHULUAN}

\subsection{Analisis Situasi}

Dalam memasuki abad ke-21, dunia pendidikan di Indonesia menghadapi tiga tantangan besar, pertama, sebagai akibat dari krisis ekonomi dunia pendidikan dituntut untuk dapat mempertahankan hasil-hasil pembangunan pendidikan yang telah dicapai.Kedua, untuk mengantisipasi era globalasasi dunia pendidikan dituntut untuk mempersiapkan sumber daya manusia yang kompeten agar mampu bersaing dalam pasar kerja global. Ketiga sejalan dengan berlakunya otonomi daerah perlu dilakukan perubahan dan penyesuaian sistem pendidikan nasional sehingga dapat mewujudkan proses pendidikan yang lebih demokratis, memperhatikan keragaman kebutuhan/ keadaan daerah dan peserta didik, serta mendorong partisipasi masyarakat.Industri akan semakin terbuka lebar, namun persaingan dengan tenaga kerja dari negara lain pun semakin besar. Mobilitas pasar kerja di kawasan ASEAN akan semakin bebas. Dengan setiap industri di ASEAN bebas masuk ke Indonesia hal ini akan berdampak terbukanya peluang sekaligus persaingan kerja yang semakin ketat antar negara-negara ASEAN(Vikaliana, Harsanti, Wulandari, \& Andayani, 2017).Begitu juga halnya bagi alumni Universitas Pembangunan Nasional Veteran Jakarta . Kurang lebih $55 \%$ alumni belum terserap di dunia kerja.

\subsection{Permasalahan Mitra}

Problematika yang dihadapi alumni perguruan tinggi di Indonesia dari tahun ke tahun adalah pekerjaan. Mereka cenderung bertindak sebagai pencari kerja (job seeker) daripada menciptakan pekerjaan (job creator).

\subsection{Solusi Yang Ditawarkan}

Program Pelatihan Rencana Bisnis Mahasiswa akan berlangsung dan merupakan bagian dari Program Mahasiswa Wirausaha .Program ini terdiri dari berberapa tahapan, yakni: sosialisasi program, seleksi peserta pelatihan, pelatihan pembuatan rencana bisnis, pembuatan rencana bisnis, 
evaluasi rencana bisnis, magang di UKM, pemberian dana untuk start-up bisnis, serta pendampingan, monitoring dan evaluasi.(Vikaliana \& Andayani, 2018)

\subsection{Target Luaran}

\begin{tabular}{|c|c|c|c|c|c|c|}
\hline No & Kategori & Sub Kategori & Wajib & $\begin{array}{l}\text { Tamba } \\
\text { han }\end{array}$ & TS & TS+1 \\
\hline \multirow[t]{3}{*}{1.} & \multirow[t]{3}{*}{ Artikel Ilmiah dimuat di jurnal } & Internasional & & & & \\
\hline & & & & $\checkmark$ & & \\
\hline & & $\begin{array}{l}\text { Nasional } \\
\text { terakreditasi }\end{array}$ & $\checkmark$ & & $\checkmark$ & \\
\hline \multirow[t]{2}{*}{2.} & \multirow[t]{2}{*}{ Artikel imiah dimuat di prosiding } & Internasional & & $\checkmark$ & & \\
\hline & & $\begin{array}{l}\text { Nasional } \\
\text { terakreditasi }\end{array}$ & $\checkmark$ & & & \\
\hline 3. & $\begin{array}{l}\text { Untuk peningkatan daya saing Invited } \\
\text { Bu Erna Saehuddin ahli MNLP untuk } \\
\text { menjadi entrepreuner yang sukses.. }\end{array}$ & Nasional & $\checkmark$ & & $\checkmark$ & \\
\hline \multirow[t]{2}{*}{4.} & \multirow[t]{2}{*}{$\begin{array}{l}\text { Model(prototipe) untuk dijadikan } \\
\text { kurikulum }\end{array}$} & $\begin{array}{l}\text { Internal } \\
\text { Kampus }\end{array}$ & $\checkmark$ & & & \\
\hline & & Nasional & $\checkmark$ & & & \\
\hline 5. & $\begin{array}{l}\text { Program } \quad \text { pengembangan } \\
\text { Entrepreunership bagi fresh graduate } \\
\text { dan daya saing yang berkelanjutan }\end{array}$ & Untuk S1 & $\checkmark$ & & $\checkmark$ & $\checkmark$ \\
\hline 6. & $\begin{array}{l}\text { Evaluasi program untuk menentukan } \\
\text { faktor } 2 \text { yg berkontribusi bagi calon } \\
\text { tenaga kerja yg siap bersaing di abad } \\
21\end{array}$ & $\begin{array}{l}\text { Internal } \\
\text { Kampus }\end{array}$ & $\checkmark$ & & $\checkmark$ & $\checkmark$ \\
\hline 7. & $\begin{array}{l}\text { Bahan referensi untuk pembentukan } \\
\text { model pembelajaran yang dibutuhkan } \\
\text { user. }\end{array}$ & $\begin{array}{l}\text { Internal } \\
\text { Kampus }\end{array}$ & & $\checkmark$ & $\checkmark$ & $\sqrt{ }$ \\
\hline
\end{tabular}

\section{PELAKSANAAN DAN METODE KEGIATAN}

\subsection{Pelaksanaan}
a. Lokasi dan Waktu
Di UPN "Veteran Jakarta " selama dua hari
b. Latar Belakang peserta
Fresh Graduate 2017/2018 pada fakultas Ekonomi Dan Bisnis UPN "Veteran" Jakarta
c. Jumlah peserta : 100 orang yang lulus seleksi

\subsection{Metode Dan Materi Kegiatan}

\subsubsection{Metode}

1. Tabulasi calon fresh graduate periode 2018

2. Melakukan seleksi untuk mengetahui tingkat kompetensi dan intelegensi

3. Seminar dan Workshop kewirausahaan

4.Evaluasi dan membantu penyaluran ke tepat kerja bagi yang berprestasi

5.Seleksi peserta untuk membuat INKUBATOR BISNIS untuk program pengembangan fresh graduate yang selanjutnya.( Tahun 2019)

\subsubsection{Materi Seminar}


a. Kenapa Kalau Ingin Sukses dan Kaya harus Jadi Pengusaha?

b. Karena 9 dari 10 Pintu Rezeki ada di Perdagangan

c. Dengan Trik BOTOL, BODOL. BOSOL, Apapun Bisnis bisa Dibuka dengan Mudah

d. Dengan Jurus 9-A, ATM, dan ATP, Semua Orang Bisa Sukses Berbisnis

e. Bisa Dimulai dengan 3-P Jenis Bisnis yang Prospektif. Apa Saja itu?

f. Ternyata Modal Bisnis itu Gampang Asal Tahu Caranya? Dimana Saja Sumbernya?

g. Tidak Ada Bisnis yang Mandeg, Stag, atau Kolaps asal Tahu Trik Meledakkan Omsetnya

h. Bisnis itu Mudah Dikembangkan Bercabang-cabang Jika Tahu Ilmu dan Caranya

2.2.3 Materi Workshop Sehari

9 Kunci Rahasia Kesuksesan Bisnis

(1) Bagaimana Cara dan Strategi Buka Bisnis Jika Hanya Punya Modal KTP?

(2) Mengapa Pebisnis harus Punya Banyak Kartu Kredit dan Bagaimana Cara Benar Memainkannya?

(3) Bagaimana Cara Buka Bisnis Langsung Ramai dan Meledak Omsetnya Selamanya?

(4) Mengapa Bisnis Harus Diback Up Property dan Bagaimana caranya Bisa Beli Property Setiap Tahun Tanpa Harus Keluar Uang Lagi?

(5) Selain Property, Bisnis harus diBack Up dengan Kebun Emas. Apa Maksudnya dan Bagaimana Cara yang Benar Beternak Emas?

(6) Mengapa Pebisnis Harus Dekat Wartawan dan Bagaimana Trik Memanfaatkan Media Massa untuk Mendongkrak Bisnis?

(7) Mengapa Bisnis Harus Dibuat Bercabang-cabang dan Difranchisekan. Bagaimana Caranya?

(8) Bagaimana Membangun Passive Income supaya Bisnis Jalan, Ownernya Jalan-jalan? Bisa Berkali-kali Umroh dan Haji, Keliling Dunia Nggak Pake Uang?

(9) Mengapa Bisnis Harus di-Leverage dengan Sedekah Brutal? Apa Dasarnya, Seperti Apa Rumusnya dan Bagaimana Caranya? Dan terakhir diberi Cara membuat proposal bisnis yang rekomended.

\section{HASIL DAN PEMBAHASAN}

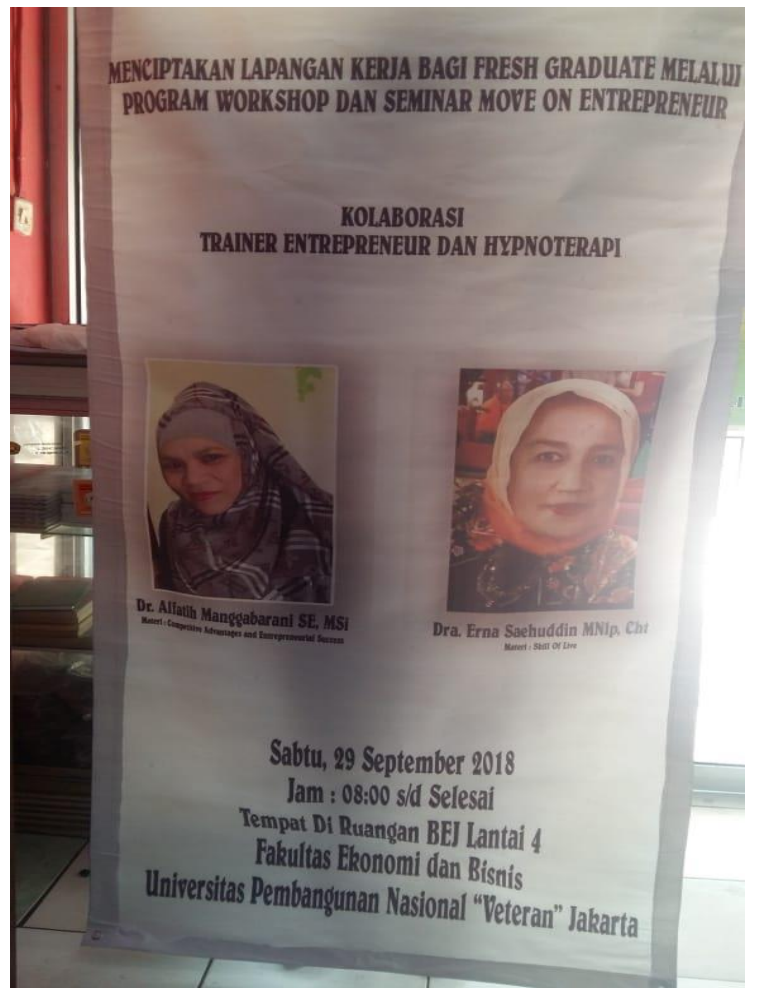




\subsection{AKTIVITAS WORKSHOP ENTREPREUNER}
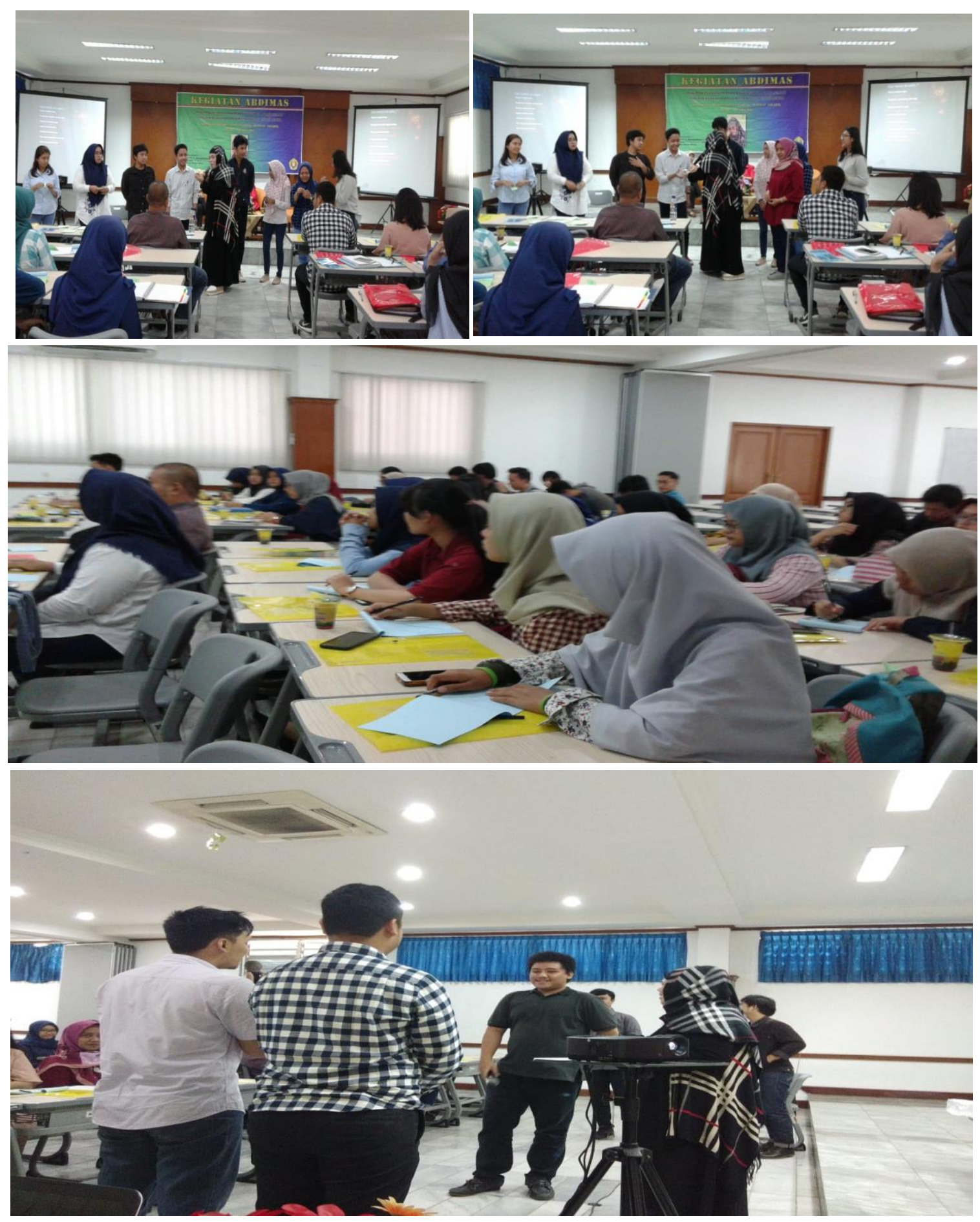

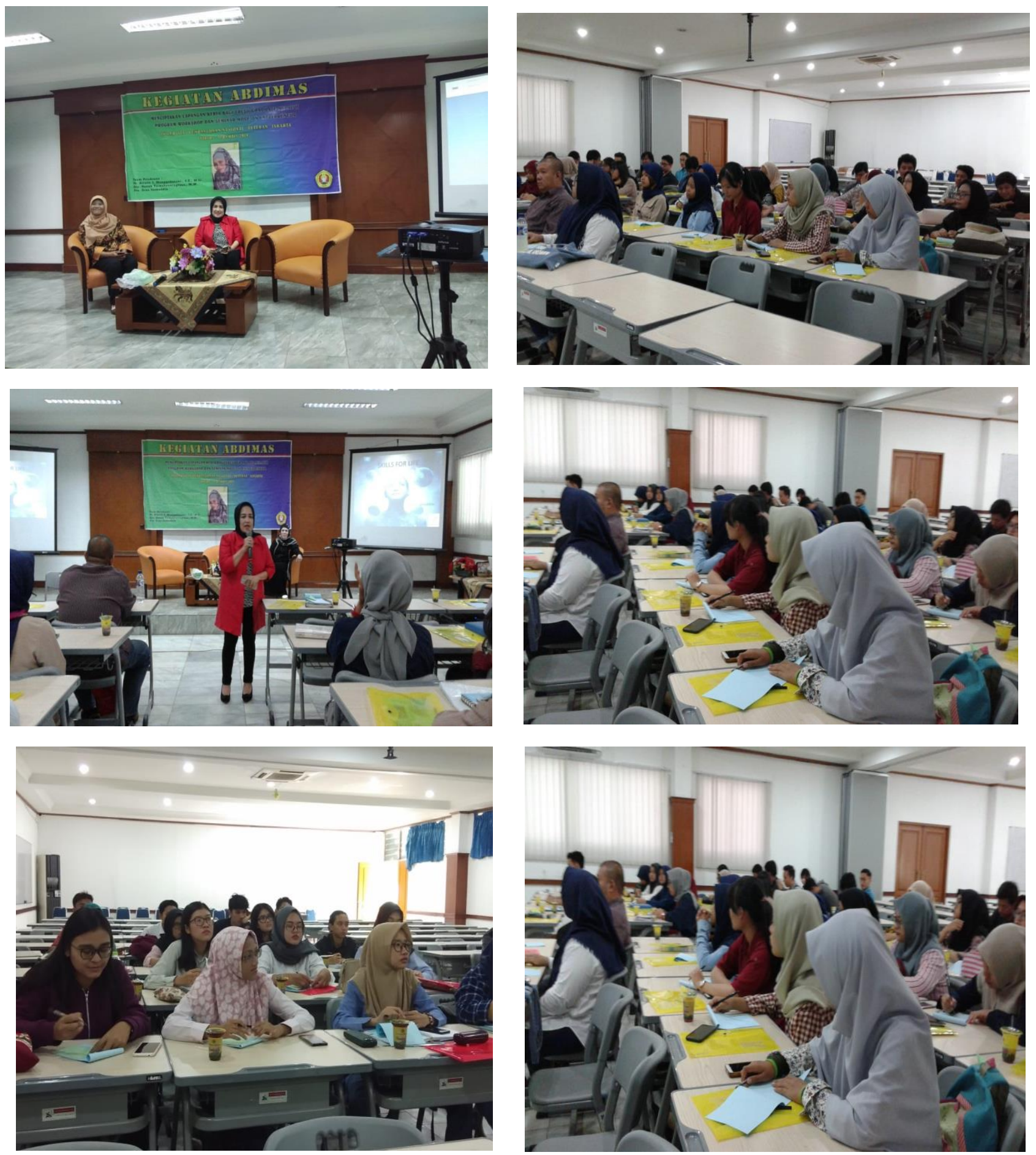

Refleksi Hasil Pelatihan Selama proses pelatihan, tim pelaksana kegiatan pengabdian melakukan pemantauan kepada peserta pelatihan sekaligus melakukan wawancara terhadap materi, metode dan instruktur dalam kegiatan ini. Secara umum guru mengatakan pelatihan ini sangat baik dan materi yang diberikan merupakan materi yang sangat dibutuhkan dalam pembelajaran matematika sedangkan instrukturnya sangat berkompoten. 


\section{Tanggapan peserta terhadap Kegiatan WORKSHOP}

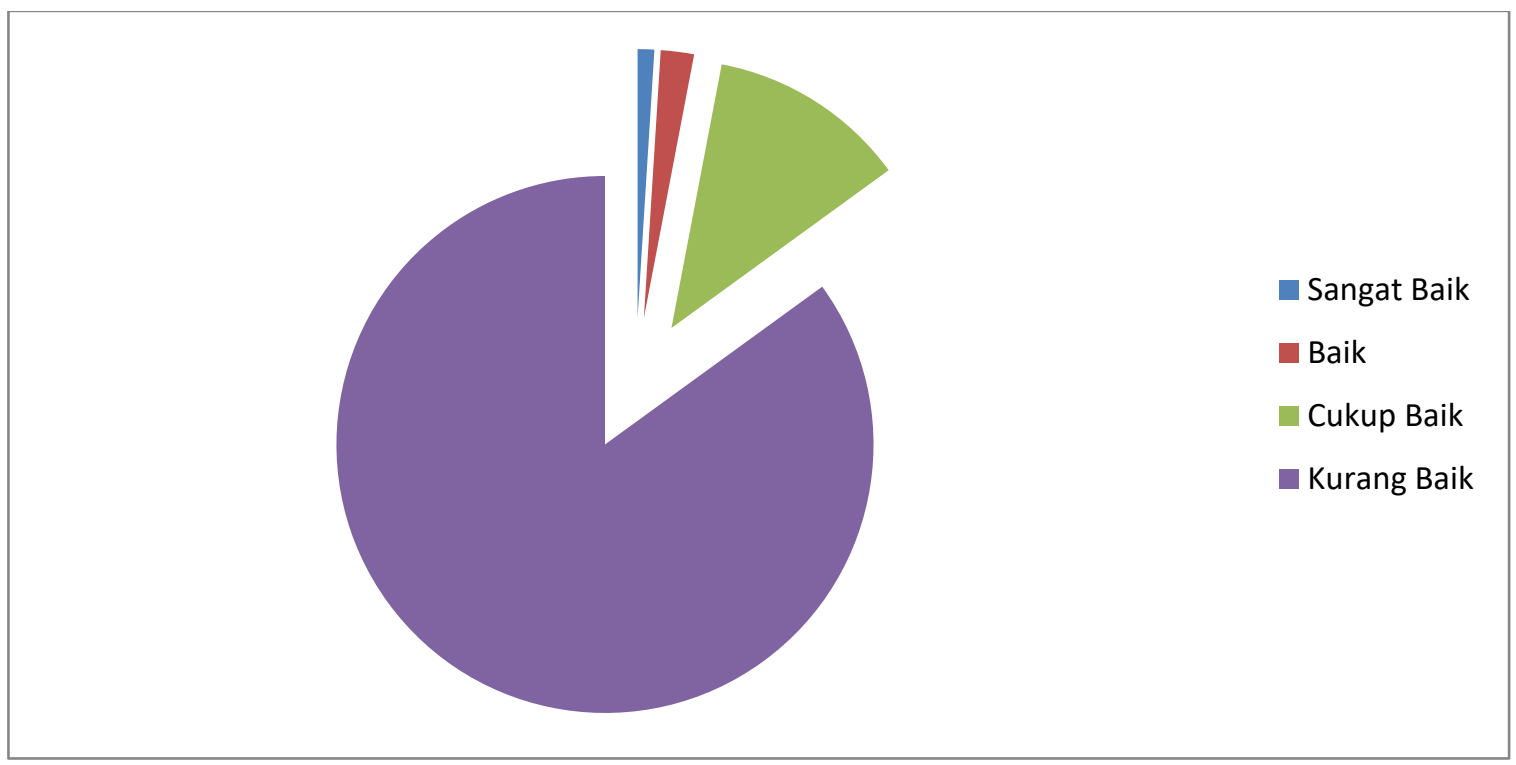

Tanggapan.Peserta.terhadap.INSTRUKTUR/NARASUMBER

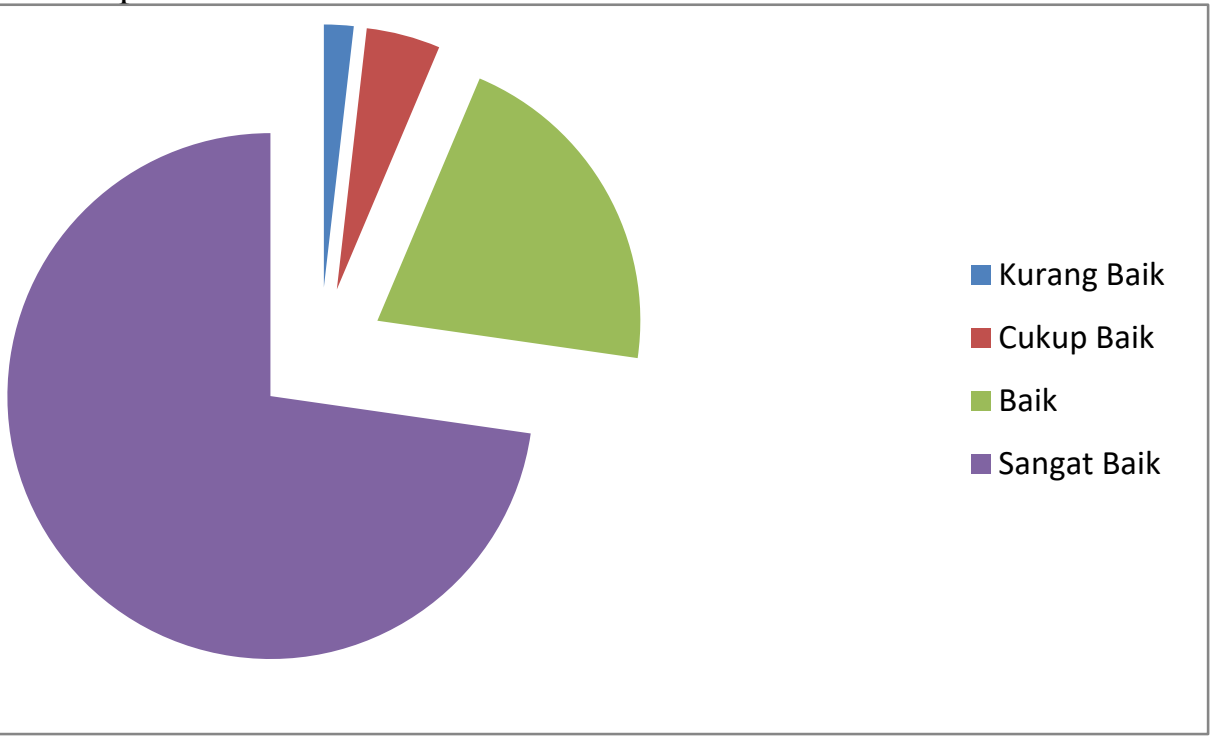

\section{PENUTUP}

Kegiatan pengabdian Ipteks bagi Masyarakat (IbM) sudah dilakukan berupa pelatihan dan workshop untuk menjadi pengusaha yang sukses dan calon karyawan yang baik.. Pelatihan diawali dengan pengenalan beberapa model dan metode bisnis real yang sederhana dan rendah modal , kemudian dilanjutkan dengan game dan pelatihan. Dari hasil diskusi dengan alumni dan mahasiswa , mulai dari awal koordinasi dan selama pelaksanaan pengabdian, mereka sangat mengharapkan pelatihan-pelatihan dan workshop sering dilakukan dan berkelanjutan terutama dalam melakukan visualisasi objek-objek bisnis dan lapangan kerja . Namun kegiatan ini diharapkan tidak berakhir pada kegiatan pengabdian, tetapi bisa dibentuk kerjasama dalam penyebaran informasi tentang perkembangan dunia bisnis dan lapangan pekerjaan yang potensil muntuk S1 .

\section{DAFTAR PUSTAKA}

Vikaliana, R., \& Andayani, A. (2018). Social Entrepreneurship: Kewirausahaan Perempuan di Bogor melalui Pengolahan Kain Perca Limbah Konveksi menjadi Aksesoris. 
https://doi.org/https://doi.org/10.21067/jpm.v3i2.2864

Vikaliana, R., Harsanti, D., Wulandari, D. S., \& Andayani, A. (2017). A Cluster Model for Increasing Performance of Small and Medium-Scale Enterprises (A Case Study in Bogor, Indonesia). Springer, Singapore. https://doi.org/https://doi.org/10.1007/978-981-287-661$4 \_15$

http://eprints.undip.ac.id/36859/1/darwanto-Peran_Entrepreneur_proceed_polines.pdf

https://journal.uc.ac.id/index.php/JEE

https://www.scribd.com/doc/140410573/KEWIRAUSAHAAN-ENTREPRENEURSHIP-JurnalMODAL-MANUSIA-DALAM-MEMBANGUN-PEREKONOMIAN

https://media.neliti.com/media/publications/195179-ID-entrepreneurial-education-danentreprene.pdf

https://media.neliti.com/media/publications/259420-motivasi-entrepreneurship-pada-mahasiswa2f47bbc8.pdf

http://eprints.undip.ac.id/36859/1/darwanto-Peran_Entrepreneur_proceed_polines.pdf

http://fe.um.ac.id/wp-content/uploads/2009/10/6-Endi-Sarwoko.pdf

https://mpra.ub.uni-muenchen.de/77076/1/MPRA_paper_77076.pdf

file:///C:/Users/nusajaya\%204/Downloads/318-Article\%20Text-2337-3-10-20180821.pdf 